\title{
Article \\ Time-Dependent Degradation of Naphthoquinones and Phenolic Compounds in Walnut Husks
}

\author{
Aljaz Medic *(D), Tilen Zamljen (D), Metka Hudina (D) and Robert Veberic (D) \\ Department of Agronomy, Biotechnical Faculty, University of Ljubljana, Jamnikarjeva 101, \\ SI-1000 Ljubljana, Slovenia; tilen.zamljen@bf.uni-lj.si (T.Z.); metka.hudina@bf.uni-lj.si (M.H.); \\ robert.veberic@bf.uni-lj.si (R.V.) \\ * Correspondence: aljaz.medic@bf.uni-lj.si; Tel.: +386-40240201
}

check for

updates

Citation: Medic, A.; Zamljen, T.; Hudina, M.; Veberic, R. TimeDependent Degradation of Naphthoquinones and Phenolic Compounds in Walnut Husks. Biology 2022, 11, 342. https:// doi.org/10.3390/biology11020342

Academic Editor: Alessandra Durazzo

Received: 3 February 2022 Accepted: 18 February 2022 Published: 21 February 2022

Publisher's Note: MDPI stays neutral with regard to jurisdictional claims in published maps and institutional affiliations.

Copyright: (C) 2022 by the authors. Licensee MDPI, Basel, Switzerland. This article is an open access article distributed under the terms and conditions of the Creative Commons Attribution (CC BY) license (https:// creativecommons.org/licenses/by/ $4.0 /)$.

\begin{abstract}
Simple Summary: Some studies have examined the degradation of individual phenolic compounds. However, the degradation of naphthoquinones has been poorly investigated, with contradicting reports. This study investigated how individual phenolic compounds and phenolic groups (e.g., naphthoquinones, flavanols, flavonols, hydroxycinnamic acids) are oxidized over time in walnut husk gratings, to better explain, or confirm, the process of the juglone release pathway. The study was designed to initially determine whether the proposed juglone synthesis pathway of hydrojuglone glucoside $\rightarrow \alpha$-hydrojuglone $\rightarrow$ juglone is indeed correct, or whether an alternative pathway is seen. The study also provides new data about the degradation of individual phenolics and phenolic groups over time when damaged tissue is exposed to the air. As phenolic compounds are considered highly beneficial to human health, increases upon processing indicate the need for further investigations into healthier food preparation processes.
\end{abstract}

Abstract: The aim of the present study was to investigate how individual phenolic compounds and phenolic groups in walnut husk gratings (e.g., naphthoquinones, flavanols, flavonols, hydroxycinnamic acids) are oxidized over time, with a particular focus on the juglone synthase pathway. Walnut husk gratings were prepared and left under 'degradation' conditions (exposure to the air, room temperature) at increasing times. Following methanol extraction of these husk gratings, the HPLC profile of methanolic extract of husk gratings exhibited twenty-six compounds over time, then hydrojuglone glucoside, $\alpha$-hydrojuglone, and juglone were detailed by HPLC-mass spectrometry. Initially (0-20 $\mathrm{min})$, the content of hydrojuglone glucoside in the husk gratings decreased by $40.4 \%$, while the content of $\alpha$-hydrojuglone increased by $20.0 \%$, and then decreased. After an initial delay (0-20 $\min$ ), juglone increased by $47.9 \%$ from 20 to $40 \mathrm{~min}$, and then decreased. This initially confirmed that hydrojuglone glucoside and $\alpha$-hydrojuglone could be considered as precursors of juglone. Different phenolic groups showed different degradation processes, although they all reached their highest content after $40 \mathrm{~min}$. This might arise from degradation of the phenols, increased free phenols, or activation of the plant defense mechanism due to damage to the tissue, similar to the effects of stress or a pathogen attack. Although it has been reported that the phenolic compounds decrease when food is processed or damaged, they showed increases, which were not indefinite, but time dependent. As phenolic compounds are considered highly beneficial to human health, increases upon processing indicate the need for further investigations into healthier food preparation processes. This is the first study on the degradation pathways of juglone, using a mass spectrometer, in which we suggest that hydrojuglone glucoside and $\alpha$-hydrojuglone are indeed the precursors of juglone. However, it is possible that there are other degradation pathways of hydrojuglone glucoside, since less juglone is synthesized than expected.

Keywords: juglone; $\alpha$-hydrojuglone; hydrojuglone glucoside; oxidation; degradation; Juglans regia; husk 


\section{Introduction}

Phenolic compounds are classified as secondary metabolites. In plants, they are composed of a diverse group of molecules that have a wide range of functions and structures, although they generally have an aromatic ring that bears one or more hydroxyl substituents. These phenolic compounds are considered the most important, numerous, and ubiquitous group of compounds in the plant kingdom [1].

Phenolic compounds are synthesized during plant development. Among their several functions in plants, they most commonly serve as part of plant defense mechanisms and are thus synthesized in various situations in response to stress, pathogen attacks, UV radiation, and other factors [2]. They are mainly classified according to the number of phenolic rings they contain, although they have also been divided according to their water solubilities: (i) water-insoluble compounds, which include lignins, condensed tannins, and the cell wall-bound hydroxycinnamic acids; and (ii) water-soluble compounds, which include quinones, flavonoids, phenylpropanoids, and phenolic acids [3].

Quinones are classified according to their specific aromatic skeleton, and from a chemical point of view, they are classified as benzoquinones, 1,4- and 1,2-naphthoquinones, furanonaphthoquinones, and anthraquinones, which are in the form of monomeric or dimeric units [4]. Most quinones belong to the groups of naphthoquinones, benzoquinones, anthraquinones, and phenanthrenequinones [5]. Of these, the naphthoquinones are of particular interest, because they occur as natural products [6]. Among the naphthoquinones, juglone (5-hydroxy-1,4-naphthoquinone) remains of great interest, because of its high chemical reactivity and allelopathic effects $[7,8]$.

Most flavonoids in plants are glycosides and, thus, they include different sugar units and acylated sugars at different positions of the polyphenol skeleton [9]. When flavonoids are associated with one or more sugar molecules, they are known as flavonoid glycosides, and when they are not associated with a sugar molecule, they are known as aglycones. In general, the aglycone forms are more active than the glycoside forms, although glycosylated flavonoids are more common in plants [10]. The flavonoids are the most important of the bioactive compounds in plants, and they have been divided into six subclasses according to their chemical structures: flavan-3-ols, flavanones, flavones, flavonols, isoflavones, and anthocyanins [3].

The second most important group of these phenolic compounds are the phenolic acids, which are present in plants in bound, rather than soluble, forms. The phenolic acids have been divided into two subgroups: hydroxybenzoic acids and hydroxycinnamic acids. Unlike the other phenolic compounds, these are acidic in character because they contain a carboxyl group. Hydroxycinnamic acids occur mainly as derivatives with a C6-C3 skeleton, whereas hydroxybenzoic acids have a C6-C1 skeleton and occur mostly as esters $[9,11]$. Visualization of different phenolic groups studied in our research can be observed in Figure 1.

Considering plants and foods in general, under stress conditions, plants respond with an increase in phenolic compounds, but once the fruit is removed from the plant, this response would not be expected to continue in the fruit itself [12]. However, for vegetables, the studies carried out have been inconclusive, or even contradictory, as the phenolic content of vegetables can increase over time, or after thermal treatments or a pathogen attack; alternatively, the phenolic content can also decrease over time [13-15]. Thermal treatments of various food matrices have been reported to promote the release of bound phenols and, thus, lead to an increase in the free phenolic fraction [16]. The increase in phenolic content in vegetables might be due to the degradation of phenols [17] or to the increase in free flavonols [18].

Some studies have examined the degradation of individual phenolic compounds [19-22]. However, the degradation of naphthoquinones has been poorly investigated, with contradicting reports $[8,23,24]$. As juglone is the most common and widely known naphthoquinone and one of the first allelochemicals discovered [7], it is also the focus of the present study. The biosynthesis of juglone remains to be fully elucidated, although the shikimate 
pathway has been suggested as the likely candidate, since several important precursors contain 1,4-naphthoquinone, $o$-succinylbenzoic acid, and 2-succinylbenzoate [25].

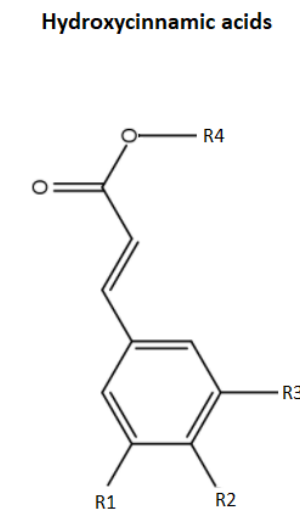

$\mathrm{R} 2=\mathrm{OH}: p$-coumaric acid

$\mathrm{R} 2=\mathrm{OH}, \mathrm{R} 3=\mathrm{OH}$ : caffeic acid

$\mathrm{R} 3=\mathrm{OCH}_{3}, \mathrm{R} 2=\mathrm{OH}$ : ferulic acid

$\mathrm{R} 1=\mathrm{OCH}_{3}, \mathrm{R} 2=\mathrm{OH}, \mathrm{R} 3=\mathrm{OCH}_{3}$ : sinapic acid

$\mathrm{R} 1=\mathrm{OH}, \mathrm{R} 2=\mathrm{OH}, \mathrm{R} 4=\mathrm{C}_{7} \mathrm{O}_{5} \mathrm{H}_{11}$ : chlorogenic acid

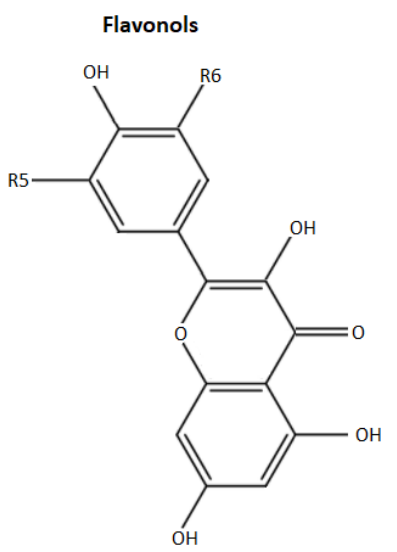

$\mathrm{R} 5=\mathrm{H}, \mathrm{R} 6=\mathrm{H}:$ kaempfero $\mathrm{R} 5=\mathrm{H}, \mathrm{R} 6=\mathrm{OH}$ : quercetin $\mathrm{R} 5=\mathrm{OH}, \mathrm{R} 6=\mathrm{OH}:$ myricetin $\mathrm{R} 5=\mathrm{H}, \mathrm{R} 6=\mathrm{OCH}_{3}$ : isorhamnetin

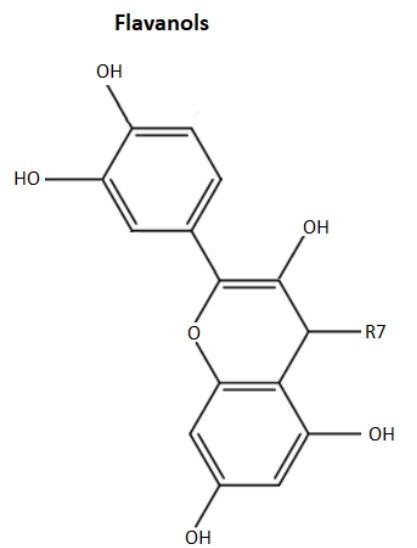

$\mathrm{R} 7=\mathrm{H}:(+)$ catechin $\mathrm{R} 7=\mathrm{C}_{15} \mathrm{O}_{6} \mathrm{H}_{14}:$ procyanidin dimer
Naphthoquinones<smiles>O=C1CCCc2ccccc21</smiles><smiles>O=C1C=CC(=O)c2ccccc21</smiles>

Figure 1. Phenolic groups identified in walnut husk gratings.

As with most plants that produce toxic secondary metabolites, juglone is stored in a nontoxic form in the tree [25]. In 1943, it was first demonstrated that juglone is not present in the root, bark, and husks of walnut, but is instead in the form of $\alpha$-hydrojuglone, which is nontoxic, but is oxidized to juglone when exposed to air [26]. Less than a decade later, it was shown that juglone is stored in walnut as the 5-glucoside of 1,4,5tri-hydroxynaphthalene [27]. This glucoside is very labile and easily hydrolyzed to glucose and $\alpha$-hydrojuglone. The conversion of the glucoside to juglone was proposed to be a two-step process, with $\beta$-glucosidase (a common soil enzyme) catalyzing its hydrolysis in the first step, followed by rapid chemical oxidation in the second step [8]. However, as indicated, this conversion has been poorly studied, and the few studies carried out have reported conflicting results.

The aim of the present study was both to investigate how individual phenolic compounds and phenolic groups (e.g., naphthoquinones, flavanols, flavonols, hydroxycinnamic acids) are oxidized over time, and to better explain, or confirm, the process of the juglone release pathway. The study was therefore designed to initially determine whether the proposed juglone synthesis pathway of hydrojuglone glucoside $\rightarrow \alpha$-hydrojuglone $\rightarrow$ juglone is indeed correct, or whether an alternative pathway is seen. The study also provides new data on various phenolic compounds, in terms of the degradation of individual phenolics and phenolic groups over time when damaged tissue is exposed to the air.

\section{Materials and Methods}

\subsection{Plant Material}

Samples of Juglans regia L. (walnut) husks were obtained on 22 September 2021, from a 25-year-old walnut tree of the French cultivar 'Franquette'. The planting density of the trees was $10 \mathrm{~m} \times 10 \mathrm{~m}$ at the Experimental Field for Nut Crops in Maribor (Slovenia; $46^{\circ} 34^{\prime} 01^{\prime \prime} \mathrm{N} ; 15^{\circ} 37^{\prime} 51^{\prime \prime} \mathrm{E} ; 275 \mathrm{~m}$ a.s.l.). The samples were collected from one tree, from the middle third of the branches on the eastern side, to obtain material that was as uniform as possible. The samples were taken to the laboratory for further analysis (Department of Agronomy, Biotechnical Faculty, University of Ljubljana, Ljubljana, Slovenia).

\subsection{Sampling and Extraction of Individual Phenolic Compounds}

Twenty healthy and undamaged walnut husks were used for the experiment. Each of the husks was grated using a standard kitchen grater (hole size, $2 \mathrm{~mm}$ ), to obtain 
uniformly damaged husk tissue gratings to maintain the most uniform conditions possible for degradation (i.e., oxidation) of the phenolic compounds. The gratings from the husks were then spread evenly in a 5-mm-thick layer on a plastic cutting board $(25 \times 35 \mathrm{~cm})$ and divided into 28 similarly-sized samples; these were left exposed to the air at room temperature. Four of the samples were randomly selected for each sampling time (i.e., four replicates per timepoint), as immediately after grating ( $0 \mathrm{~min}$ ), and at 20, 40, $60,180,360$, and $540 \mathrm{~min}$ exposure to degradation (in air, at room temperature). This provided an evaluation of the rate of degradation of each phenolic compound and of the different phenolic groups over time. At these specified times, the samples were placed in liquid nitrogen to prevent further degradation, and then ground using a mortar prior to the methanol extraction.

The phenolic compounds were extracted following the protocol previously described by Medic et al. [28]. Briefly, $0.25 \mathrm{~g}$ of husk gratings was extracted using absolute methanol (1:20, w/v, respectively). The samples were vortexed (Top-Mix 94500; Heidolph, Schwabach, Germany) for $30 \mathrm{~s}$, and then sonicated (Sonis 4; Iskra pio, Sentjernej, Slovenia) in iced water for $60 \mathrm{~min}$. Following the extraction, the samples were centrifuged (5810 R; Eppendorf, Hamburg, Germany) at $10,000 \times g$ for $10 \mathrm{~min}$ at $4{ }^{\circ} \mathrm{C}$, filtered through $0.2-\mu \mathrm{m}$ polyamide filters (Chromafil AO 20/25; Macherey-Nagel, Düren, Germany), and transferred to vials for further analysis.

\subsection{Identification and Quantification of the Phenolic Compounds Using HPLC and Mass Spectrometry}

The initial identification of all 26 of the phenolic compounds was carried out using UHPLC (Vanquish; Thermo Scientific, Waltham, MA, USA), coupled with tandem mass spectrometry (LTQ XL; Thermo Scientific, Waltham, MA, USA) with heated electrospray ionization.

For the separation of the compounds through UHPLC, a C18 column (Gemini; Phenomenex, Torrance, CA, USA) was used with a flow rate of $0.6 \mathrm{~mL} / \mathrm{min}$, under similar conditions to those previously described [28]. The solvents used were: A, $0.1 \%$ formic acid with $3 \%$ acetonitrile in bi-distilled water $(v / v / v) ; \mathrm{B}, 0.1 \%$ formic acid with 3\% bidistilled water in acetonitrile $(v / v / v)$. The gradient used was as follows: $0-15 \mathrm{~min}, 5-20 \%$ B; 15-20 min, 20-30\% B; 20-25 min, 30-50\% B; 25-30 min, 50-90\% B; 30-35 min, 90-100\% B; 35-45 $\mathrm{min}, 100-5 \% \mathrm{~B} ; 45-50 \mathrm{~min}, 5 \% \mathrm{~B}$.

The mass spectrometer was operated in negative ion mode, with the following parameters used [28]: sheath temperature, $150{ }^{\circ} \mathrm{C}$; sheath gas, $30 \mathrm{arb}$; auxiliary gas, 20 arb; ion spray voltage, $3.2 \mathrm{kV}$; capillary temperature, $300{ }^{\circ} \mathrm{C}$; capillary voltage, $-23.99 \mathrm{~V}$; and tube lens, - $57.36 \mathrm{~V}$; collision gas, helium; collision energy, $35 \mathrm{eV}$; scans performed, from $\mathrm{m} / \mathrm{z} 50$ to 2000; data acquisition, Xcalibur 2.2 software (Thermo Fisher Scientific Institute, Waltham, MA, USA). The UHPLC-separated compounds were fragmented and identified according to data shown previously [29,30].

For the quantification over time of the phenolic compounds, due to the low content of hydrojuglone glucoside, $\alpha$-hydrojuglone, and juglone in the extracted samples, and to provide their precise quantification, these were analyzed using the UHPLC-mass spectrometry system (Vanquish; LTQ XL). The remaining compounds were quantified using the UHPLC system with a photodiode array detector at $280 \mathrm{~nm}$. Where commercial standards were available, the phenolic compounds are expressed according to their standard; otherwise, the nearest available standard was used. The total analyzed phenolic content represents the sum of all of the individually quantified phenolic compounds.

\subsection{Chemicals}

The following standards were used for these analyses: quercetin-3-glucoside and procyanidin B1 (Fluka Chemie GmbH, Buchs, Switzerland); (+)catechin (Roth, Karlsruhe, Germany); (-)epicatechin, quercetin-3-rhamnoside, quercetin-3-galactoside, neochlorogenic acid (3-caffeoylquinic acid), juglone (5-hydroxy-1,4-naphthoquinone), and gallic acid 
(Sigma-Aldrich Chemie GmbH, Steinheim, Germany); quercetin-3-xyloside, quercetin-3arabinopyranoside, and quercetin-3-arabinofuranoside (Apin Chemicals, Abingdon, UK).

The chemicals for the mobile phases (acetonitrile, formic acid) were HPLC-MS grade, and the absolute methanol used for the extractions was HPLC grade (all from Fluka Chemie $\mathrm{GmbH}$, Buchs, Switzerland). The water used was bi-distilled and purified through a Milli-Q water purification system (Millipore, Bedford, MA, USA).

\subsection{Statistical Analysis}

Data were analyzed using Microsoft Excel 2016 and R commander, version 2.7.1 (package Rcmdr) (Team R.D.C., 2008, Stanford, CA, USA). Data are expressed as means \pm standard errors. One-way analysis of variance (ANOVA) with Tukey tests were used to detect significant differences between data. Statistical means were calculated at a 95\% confidence level.

\section{Results and Discussion}

\subsection{Identification of Individual Phenolic Compounds}

The 26 compounds identified are given in Table 1, along with their $\mathrm{MS}^{2}$ fragments and the standards that were used for their quantification.

Juglone (5-hydroxy-1,4-naphthoquinone) was identified using a juglone standard according to its fragmentation pattern MS $m / z 173[\mathrm{M}-\mathrm{H}]^{-}$and $\mathrm{MS}^{2} m / z 155[\mathrm{M}-\mathrm{H}$ $\left.-\mathrm{H}_{2} \mathrm{O}\right]^{-}, 145\left[\mathrm{M}-\mathrm{H}-\mathrm{CO}^{-}, 129\left[\mathrm{M}-\mathrm{H}-\mathrm{CO}_{2}\right]^{-}\right.$, and $111\left[\mathrm{M}-\mathrm{H}-\mathrm{CO}_{2}-\mathrm{H}_{2} \mathrm{O}\right]^{-}$. Hydrojuglone glucoside MS $m / z 337$ defined the loss of a hexosyl moiety (-162) and was identified according to the specific fragmentation pattern of $\alpha$-hydrojuglone $(1,4,5-$ trihydroxy-1,4-naphthoquinone) MS $m / z 175[\mathrm{M}-\mathrm{H}]^{-}$and $\mathrm{MS}^{2} m / z 157\left[\mathrm{M}-\mathrm{H}-\mathrm{H}_{2} \mathrm{O}\right]^{-}$, and $147\left[\mathrm{M}-\mathrm{H}-\mathrm{CO}^{-}\right.$, and $131\left[\mathrm{M}-\mathrm{H}-\mathrm{CO}_{2}\right]^{-}[30,31]$. The fragmentation patterns of the remaining compounds can be found in the previous studies by Medic et al. [29,30,32].

Table 1. Tentative identification by mass spectrometry fragmentation of the 26 phenolic compounds from the husks of Juglans regia L., and the standards that were used for their quantification.

\begin{tabular}{|c|c|c|c|c|}
\hline Phenolic & $\begin{array}{l}\text { Retention } \\
\text { Time (min) }\end{array}$ & $\begin{array}{c}(\mathbf{M}-\mathbf{H})^{-} \\
(m / z)\end{array}$ & $\begin{array}{l}\mathrm{MS}^{2} \\
(\mathrm{~m} / \mathrm{z})\end{array}$ & Quantification Standard \\
\hline \multicolumn{5}{|l|}{ Naphthoquinones } \\
\hline Dihydroxytetralone hexoside & 13.04 & 339 & 159,177 & Juglone \\
\hline Hydrojuglone glucoside & 16.26 & 337 & 175 & Juglone \\
\hline Hydrojuglone derivative pentoside 1 & 17.98 & 435 & 303,285 & Juglone \\
\hline Hydrojuglone derivative pentoside 2 & 18.26 & 435 & 303,285 & Juglone \\
\hline Trihydroxytetralone derivative & 19.06 & 491 & 271,331 & Juglone \\
\hline Hydrojuglone rhamnoside & 20.64 & 321 & 175 & Juglone \\
\hline Trihydroxytetralone galloyl hexoside & 20.76 & 507 & 331,271 & Juglone \\
\hline Hydrojuglone derivative pentoside 3 & 21.27 & 435 & 303,285 & Juglone \\
\hline$\alpha$-Hydrojuglone & 28.21 & 175 & $131,147,157$ & Juglone \\
\hline Juglone (5-hydroxy-1,4-naphthoquinone) & 29.99 & 173 & $\begin{array}{l}155,145,129 \\
111\end{array}$ & Juglone \\
\hline $\begin{array}{l}\text { Juglanin B } \\
\text { Flavanols }\end{array}$ & 31.37 & 327 & 312,253 & Juglone \\
\hline Procyanidin dimer 1 & 10.38 & 577 & $425,407,289$ & Procyanidin B1 \\
\hline Procyanidin dimer 2 & 11.47 & 577 & $425,407,289$ & Procyanidin B1 \\
\hline (+) Catechin & 12.22 & 289 & $245,205,179$ & (+) Catechin \\
\hline$(-)$ Epicatechin & 14.53 & 289 & $245,205,179$ & (-) Epicatechin \\
\hline Procyanidin dimer 3 & 15.53 & 577 & $425,407,289$ & Procyanidin B1 \\
\hline Procyanidin dimer 4 & 16.89 & 577 & $425,407,289$ & Procyanidin B1 \\
\hline (epi) Catechin derivative & 20.17 & 441 & 289 & $(+)$ Catechin \\
\hline
\end{tabular}


Table 1. Cont.

\begin{tabular}{|c|c|c|c|c|}
\hline Phenolic & $\begin{array}{l}\text { Retention } \\
\text { Time (min) }\end{array}$ & $\begin{array}{c}(\mathbf{M}-\mathbf{H})^{-} \\
(m / z)\end{array}$ & $\begin{array}{l}\mathrm{MS}^{2} \\
(\mathrm{~m} / z)\end{array}$ & Quantification Standard \\
\hline \multicolumn{5}{|l|}{ Flavonols } \\
\hline Quercetin-3-galactoside & 20.53 & 463 & 301 & Quercetin-3-galactoside \\
\hline Quercetin-3-xyloside & 21.56 & 433 & 301 & Quercetin-3-xyloside \\
\hline Quercetin-3-arabinopyranoside & 21.73 & 433 & 301 & Quercetin-3-arabinopyranoside \\
\hline Quercetin-3-arabinofuranoside & 22.21 & 433 & 301 & Quercetin-3-arabinofuranoside \\
\hline Quercetin-3-rhamnoside & 22.43 & 447 & 301 & Quercetin-3-rhamnoside \\
\hline \multicolumn{5}{|l|}{ Hydroxycinnamic acids } \\
\hline $\begin{array}{l}\text { Neochlorogenic acid (3-caffeoylquinic } \\
\text { acid) }\end{array}$ & 9.36 & 353 & $191,179,135$ & Neochlorogenic acid \\
\hline 3-p-Coumaroylquinic acid & 12.01 & 337 & $163,191,173$ & Neochlorogenic acid \\
\hline \multicolumn{5}{|l|}{ Remaining phenolic compounds } \\
\hline Gallic acid derivative & 21.99 & 489 & 271,313 & Gallic acid \\
\hline
\end{tabular}

$[\mathrm{M}-\mathrm{H}]^{-}$, pseudo-molecular ion identified in negative ion mode.

\subsection{Degradation of the Individual Phenolic Compounds over Time}

When considering the individual phenolic compounds hydrojuglone glucoside, $\alpha$ hydrojuglone, and juglone, these were examined in more detail because their relationship has been unclear. Furthermore, studies have been contradictory in terms of whether hydrojuglone glucoside and $\alpha$-hydrojuglone are the precursors for juglone formation [8] or whether there are other precursors from which juglone is formed [23,24]. With the use of UHPLC-MS, their levels over time can be better determined, as even without enzymatic studies, the content of the precursors should decrease following oxidation, while the juglone content should increase, even if only for a short period of time. The time-courses for the degradation in air at room temperature of hydrojuglone glucoside, $\alpha$-hydrojuglone, and juglone in the walnut husk gratings are shown in Figure 2.

From Figure 2, it can be seen that degradation of the hydrojuglone glucoside, $\alpha$ hydrojuglone, and juglone in the walnut husk gratings was relatively rapid, with most changes occurring in the first $60 \mathrm{~min}$. Hydrojuglone glucoside degradation was relatively high over the first $20 \mathrm{~min}$, as a decrease from 15.8 to $9.4 \mathrm{~g} / \mathrm{kg}$ fresh weight (FW), representing a significant $40.5 \%$ loss $(p<0.001$ ) (Figure $2 \mathrm{~A}$ ). The degradation then slowed to a near minimum of $2.6 \mathrm{~g} / \mathrm{kg}$ FW by $180 \mathrm{~min}$. Figure $2 \mathrm{~B}, \mathrm{C}$ shows that the rates of degradation of $\alpha$-hydrojuglone and juglone were different from hydrojuglone glucoside. Here, $\alpha$ hydrojuglone increased from 0.15 to $0.18 \mathrm{~g} / \mathrm{kg} \mathrm{FW}$ in the first $20 \mathrm{~min}(+20.0 \% ; p<0.05)$, and then gradually decreased to the minimum level of $0.02 \mathrm{~g} / \mathrm{kg}$ FW by $360 \mathrm{~min}$. For juglone, after an initial delay with no significant change $(0.7 \mathrm{~g} / \mathrm{kg} \mathrm{FW}, 0-20 \mathrm{~min})$, it significantly increased to $1.05 \mathrm{~g} / \mathrm{kg} \mathrm{FW}(+47.9 \%)$ from $20-40 \mathrm{~min}$, before decreasing to its near minimum of $0.57 \mathrm{~g} / \mathrm{kg}$ FW by $180 \mathrm{~min}$. As hydrojuglone glucoside content, in $20 \mathrm{~min}$, decreased by $6.4 \mathrm{~g} / \mathrm{kg}\left(1.9 \times 10^{-2} \mathrm{~mol}\right)$, while the content of juglone, in $40 \mathrm{~min}$, increased only by $0.03 \mathrm{~g} / \mathrm{kg}\left(1.7 \times 10^{-4} \mathrm{~mol}\right)$, there was the possibility that other additional degradation pathways of hydrojuglone glucoside were possible, as less juglone is synthesized than the one expected.

These dynamics, whereby hydrojuglone glucoside initially decreased rapidly while $\alpha$-hydrojuglone increased more slowly, accompanied by a delayed increase in juglone, indicate that Duroux et al. [8] were correct in their prediction of the juglone synthesis pathway. Thus, hydrojuglone glucoside and $\alpha$-hydrojuglone indeed appear to be the precursors of juglone, in this order (Figure 3). However, enzymatic studies are still needed to confirm this pathway of juglone synthesis. All of the data for the time-courses of degradation of the further individual compounds are given in Supplementary Material Table S1. As can be seen in different phenolic groups, the content of all individual phenolic compounds decreased with time (Supplementary Material Table S1). 

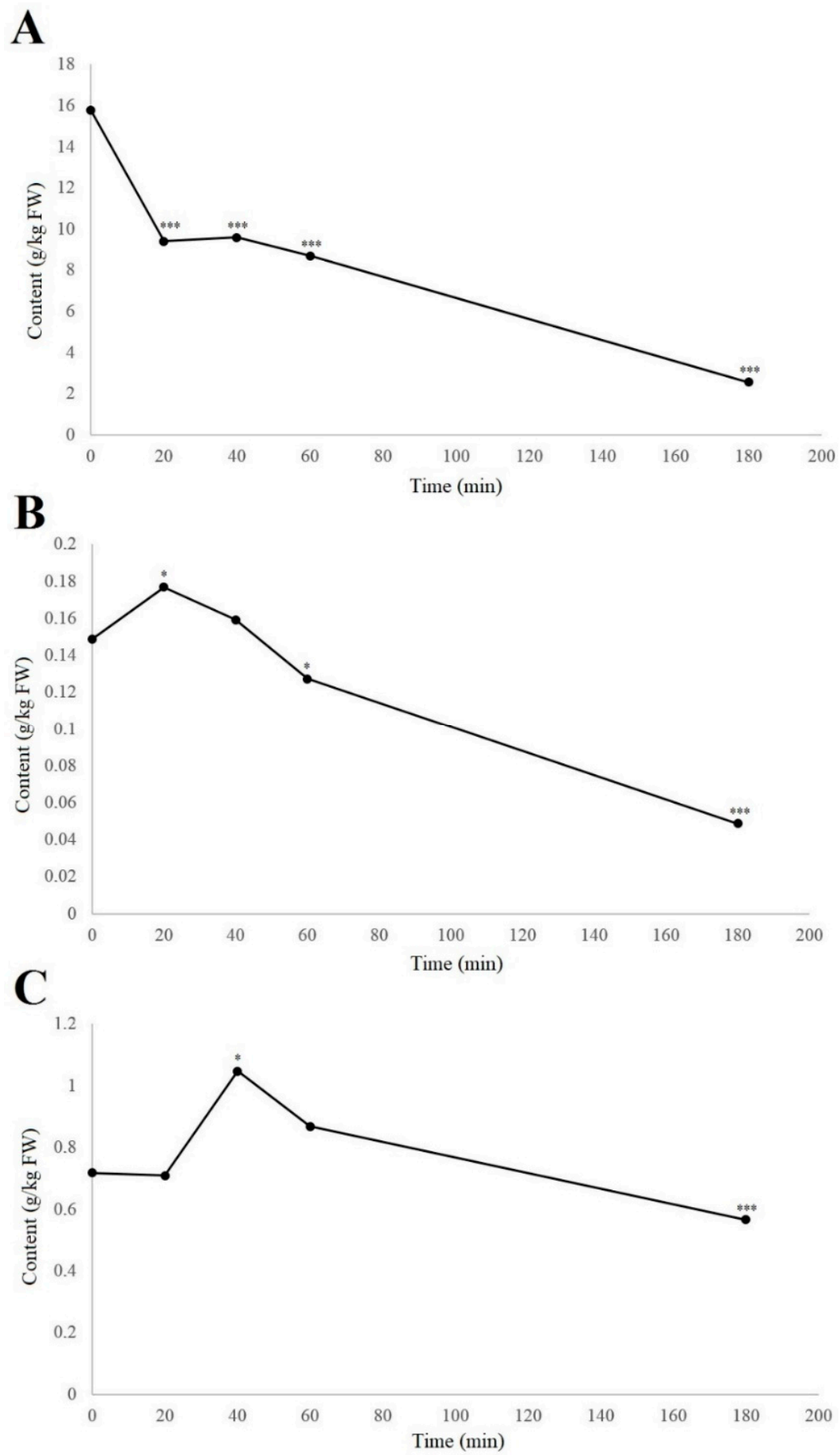

Figure 2. Time-courses of degradation (air, room temperature) of hydrojuglone glucoside (A), $\alpha$ hydrojuglone (B), and juglone $(\mathbf{C})$ levels in the walnut husk gratings. Data are means \pm standard errors $(n=4) .{ }^{*} p<0.05 ;{ }^{* *} p<0.001$ versus $0 \mathrm{~h}$ control (ANOVA, with Dunnett's test).

\subsection{Degradation of Different Phenolic Groups over Time}

When considering the groups of phenolic compounds, the time-courses of four phenolic groups were followed, as total naphthoquinones, flavanols, flavonols, and hydroxycinnamic acids. The analysis of the hydroxybenzoic acids is not included here as this 'group' contained only one example. The others are shown in Figure 4, along with the dynamics of the total analyzed phenolics content. 
<smiles>Oc1ccc(O[Te])c2c(O)cccc12</smiles>

Hydrojuglone glucoside<smiles>Oc1ccc(O)c2c(O)cccc12</smiles>

$\alpha$-Hydrojuglone<smiles>O=C1C=CC(=O)C2C(O)=CC=CC12</smiles>

Juglone

Figure 3. Proposed pathway for juglone synthesis.

A

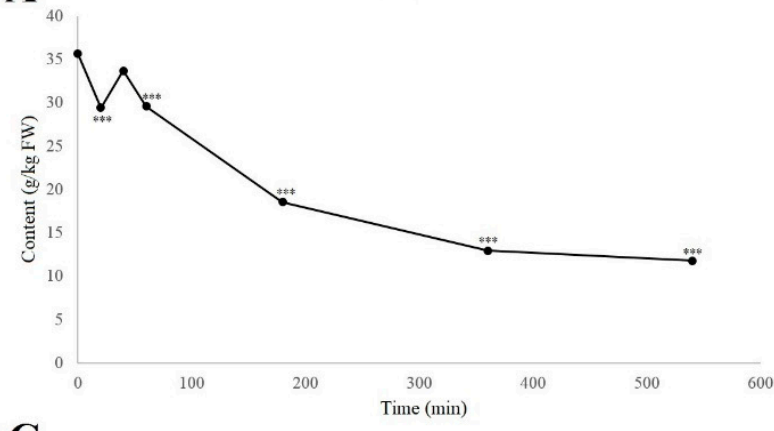

C

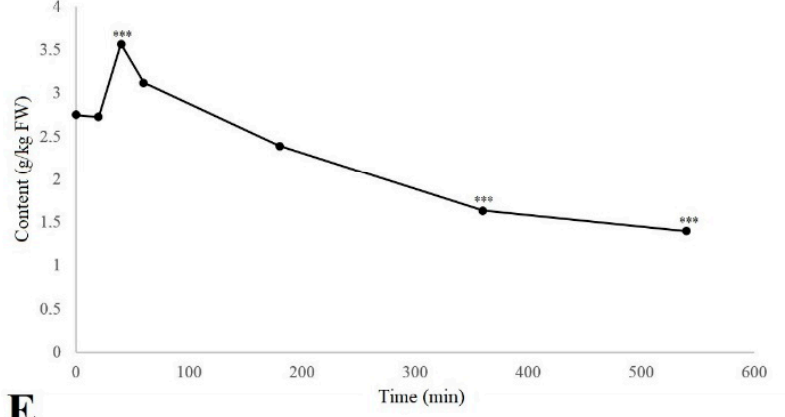

E

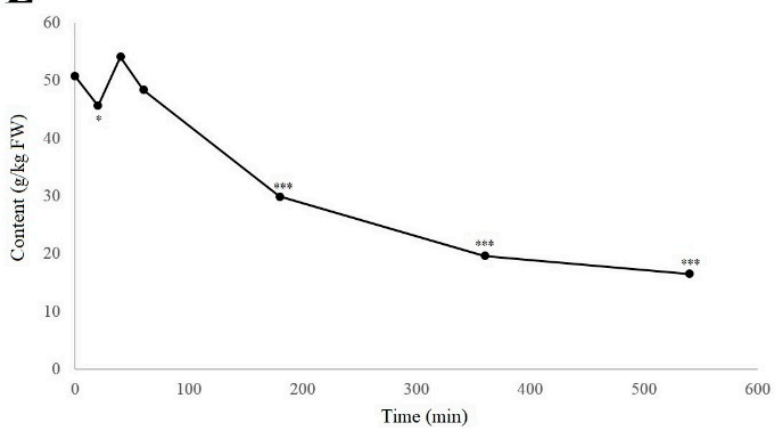

\section{B}

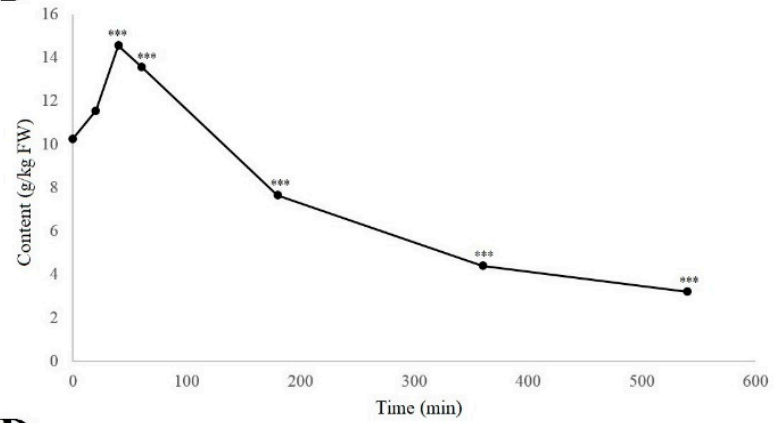

D

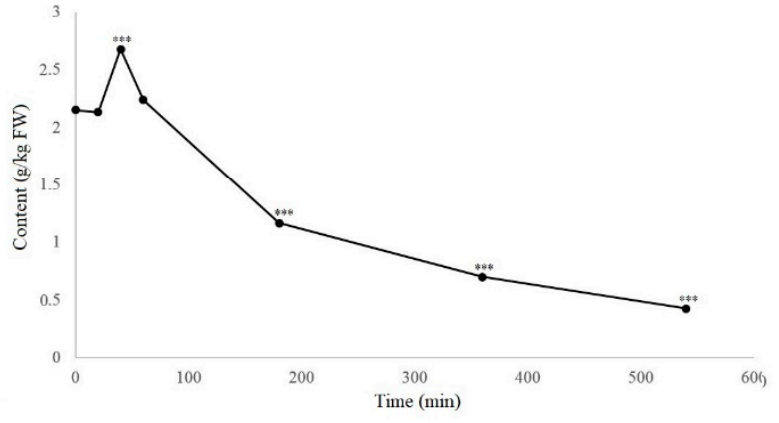

Figure 4. Time-courses of degradation (air, room temperature) of the groups of total naphthoquinones (A), flavanols (B), flavonols (C), and hydroxycinnamic acids (D), and for the total analyzed phenolics content $(\mathbf{E})$, in the walnut husk gratings. Data are means \pm standard errors $(n=4) .{ }^{*} p<0.05$; $* * * p<0.001$ versus $0 \mathrm{~h}$ control (ANOVA, with Dunnett's test).

As can be seen from Figure 4, these different phenolic groups showed different degradation rates; however, all phenolic groups, and the total analyzed phenolic compounds, reached the highest levels at 40 min of degradation (Table S1). The total naphthoquinones significantly decreased from 35.7 to $29.4 \mathrm{~g} / \mathrm{kg}$ FW from 0 to $20 \mathrm{~min}(-17.5 \%$; $p<0.001)$, 
which was reversed from 20 to $40 \mathrm{~min}$ before a gradual decrease to $12.95 \mathrm{~g} / \mathrm{kg}$ FW by $360 \mathrm{~min}$. This matches up with the changes in hydrojuglone glucoside, $\alpha$-hydrojuglone and juglone (Figure 2), which suggested that the precursor content decreased in the first $20 \mathrm{~min}$, followed by the formation of the secondary compounds, whereby the total content increased before being further oxidized or lost $[19,20]$. The total flavanols showed different dynamics to the naphthoquinones, but were very similar to both the flavonols and hydroxycinnamic acids. Here, the total flavanols, flavonols, and hydroxycinnamic acids showed no significant changes from 0-20 $\mathrm{min}$, and then reached their highest levels after $40 \mathrm{~min}$, before gradually decreasing. This effect has also been seen under different thermal treatments and for pathogen attacks, where the content of the phenolic compounds increased $[13,16,17,29]$. Thermal treatments also promote the release of bound phenols and lead to an increased free phenolic fraction [16], which appears to be similar to when the plant tissue is subjected to damage and oxidation, as in the present study. Thus, the increase in the phenolic content in the first $40 \mathrm{~min}$ might be due to their degradation or to an increase in the free phenols, as previously suggested by Crozier et al. [17] and Stewart et al. [18].

As phenolic compounds are considered to be highly beneficial for human health [33,34], this study might have a broader impact. The content of the phenolic compounds in food is believed to decrease when the food is processed or damaged (e.g., cut, bruised) [35]; however, as we see here, instead of decreasing, the phenolic compounds increased due to the breakdown of phenols or an increase in free phenols [17]. Moreover, this increase was not indefinite, but time dependent. Therefore, several studies have reported increased phenolic compounds during thermal treatments [13,16,17], while others have reported decreases [14,15], which indicates that further studies should be conducted to determine whether this is due to the type of food processing or to the timing of the processing method, as proposed. If this is true, 'correctly' treated foods could have higher phenolic content than unprocessed foods, as previously suggested by Minatel et al. [35], which could lead to healthier food preparation processes in the future.

\section{Conclusions}

A total of 26 phenolic compounds were identified and quantified, of which, hydrojuglone glucoside, $\alpha$-hydrojuglone, and juglone were identified in detail using UHPLC-MS Hydrojuglone glucoside, $\alpha$-hydrojuglone, and juglone were studied in more detail because their relationships to each other are unclear and studies have been contradictory as to whether hydrojuglone glucoside and $\alpha$-hydrojuglone are truly the precursors for the formation of juglone or whether there are other precursors from which juglone is formed. We suggest that hydrojuglone glucoside and $\alpha$-hydrojuglone are indeed the precursors of juglone, but further enzymatic studies should be performed to confirm this definitively. Interestingly, different phenolic groups have shown different degradation processes, but all phenolic groups reached their highest content $40 \mathrm{~min}$ after tissue damage and degradation. This increase in phenolic content in the first $40 \mathrm{~min}$ might be due to oxidation of inactive forms of phenols that were bound with sugars, an increase in free phenols, or through the plant defense mechanism due to the damaged tissue, similar to stress or pathogen attacks. It has been indicated that the phenolic compounds decrease when foods are processed or damaged, but instead, here, the phenolic compounds increased. This increase was not indefinite, but time dependent. As phenolic compounds are considered to be highly beneficial to human health, this study might have broader impacts, as it indicates the need for further investigations into healthier food preparation processes for immediate consumption. This is the first study on the degradation pathways of juglone using a mass spectrometer, in which we suggest that hydrojuglone glucoside and $\alpha$-hydrojuglone are indeed the precursors of juglone. However, it is possible that there are other degradation pathways of hydrojuglone glucoside, since less juglone is synthesized than expected. For future studies, isolation of hydrojuglone glucoside is inevitable, to further test whether juglone is the only product compound or whether there are other degradation products 
formed from hydrojuglone glucoside. As seen with the formation of juglone, the amounts are small and it may be difficult to confirm their structures by NMR.

Supplementary Materials: The following are available online at https:/ /www.mdpi.com/article/10 $.3390 /$ biology11020342/s1. Table S1: Time-course data for the 26 phenolic compounds and the total phenolic group content from the husks of $J$. regia.

Author Contributions: Conceptualization, A.M. and R.V.; data curation, A.M.; formal analysis, A.M. and T.Z.; funding acquisition, M.H.; investigation, A.M. and T.Z.; methodology, A.M. and R.V.; project administration, R.V.; resources, A.M. and M.H.; software, A.M.; supervision, R.V.; validation, R.V.; visualization, A.M.; writing—original draft, A.M.; writing—review and editing, M.H., T.Z. and R.V. All authors have read and agreed to the published version of the manuscript.

Funding: This study is part of program P4-0013-0481, which is funded by the Slovenian Research Agency (ARRS).

\section{Institutional Review Board Statement: Not applicable.}

Informed Consent Statement: Not applicable.

Data Availability Statement: Part of the data presented in this study are available in the Supplementary Material. The remaining data presented in this study are available upon reasonable request from the corresponding author. The remaining data are not publicly available due to privacy.

Conflicts of Interest: The authors declare that they have no known competing financial interests or personal relationships that could appear to have influenced the work reported here.

\section{References}

1. Robards, K.; Prenzler, P.D.; Tucker, G.; Swatsitang, P.; Glover, W. Phenolic compounds and their role in oxidative processes in fruits. Food Chem. 1999, 66, 401-436. [CrossRef]

2. Naczk, M.; Shahidi, F. Extraction and analysis of phenolics in food. J. Chromatogr. A 2004, 1054, 95-111. [CrossRef]

3. Haminiuk, C.W.I.; Maciel, G.M.; Plata-Oviedo, M.S.V.; Peralta, R.M. Phenolic compounds in fruits-An overview. Int. J. Food Sci. 2012, 47, 2023-2044. [CrossRef]

4. Lemos, T.L.G.; Monte, F.J.Q.; Santos, A.K.L.; Fonseca, A.M.; Santos, H.S.; Oliveira, M.F.; Costa, S.M.O.; Pessoa, O.D.L.; Braz-Filho, R. Quinones from plants of northeastern Brazil: Structural diversity, chemical transformations, NMR data and biological activities. Nat. Prod. Res. 2007, 21, 529-550. [CrossRef] [PubMed]

5. Futuro, D.O.; Ferreira, P.G.; Nicoletti, C.D.; Borba-Santos, L.P.; Silva, F.C.D.; Rozental, S.; Ferreira, V.F. The antifungal activity of naphthoquinones: An integrative review. Anais da Academia Brasileira de Ciências 2018, 90, 1187-1214. [CrossRef]

6. Kumagai, Y.; Shinkai, Y.; Miura, T.; Cho, A.K. The chemical biology of naphthoquinones and its environmental implications. Annu. Rev. Pharmacol. Toxicol. 2012, 52, 221-247. [CrossRef]

7. Medic, A.; Zamljen, T.; Slatnar, A.; Hudina, M.; Veberic, R. Is juglone the only naphthoquinone in Juglans regia L. with allelopathic effects? Agriculture 2021, 11, 784. [CrossRef]

8. Duroux, L.; Delmotte, F.M.; Lancelin, J.-M.; Kéravis, G.; Jay-Allemand, C. Insight into naphthoquinone metabolism: $\beta$-glucosidasecatalysed hydrolysis of hydrojuglone $\beta$-d-glucopyranoside. Biochem. J. 1998, 333, 275-283. [CrossRef]

9. Tsao, R. Chemistry and biochemistry of dietary polyphenols. Nutrients 2010, 2, 1231-1246. [CrossRef]

10. Kaur, C.; Kapoor, H.C. Antioxidants in fruits and vegetables-The millennium's health. Int. J. Food Sci. 2001, 36, 703-725. [CrossRef]

11. Rice-Evans, C.A.; Packer, L. Flavonoids in Health and Disease, 2nd ed.; CRC Press: Boca Raton, FL, USA, 2003. [CrossRef]

12. Gonçalves, E.M.; Pinheiro, J.; Abreu, M.; Brandão, T.R.S.; Silva, C.L.M. Carrot (Daucus carota L.) peroxidase inactivation, phenolic content and physical changes kinetics due to blanching. J. Food Eng. 2010, 97, 574-581. [CrossRef]

13. Turkmen, N.; Sari, F.; Velioglu, Y.S. The effect of cooking methods on total phenolics and antioxidant activity of selected green vegetables. Food Chem. 2005, 93, 713-718. [CrossRef]

14. González-Gómez, D.; Cardoso, V.; Bohoyo, D.; Ayuso, M.; Delgado-Adamez, J. Application of experimental design and response surface methodology to optimize the procedure to obtain a bactericide and highly antioxidant aqueous extract from orange peels. Food Control 2014, 35, 252-259. [CrossRef]

15. Conidi, C.; Rodriguez-Lopez, A.D.; Garcia-Castello, E.M.; Cassano, A. Purification of artichoke polyphenols by using membrane filtration and polymeric resins. Sep. Purif. Technol. 2015, 144, 153-161. [CrossRef]

16. Alfeo, V.; Bravi, E.; Ceccaroni, D.; Sileoni, V.; Perretti, G.; Marconi, O. Effect of baking time and temperature on nutrients and phenolic compounds content of fresh sprouts breadlike product. Foods 2020, 9, 1447. [CrossRef]

17. Crozier, A.; Lean, M.E.J.; McDonald, M.S.; Black, C. Quantitative analysis of the flavonoid content of commercial tomatoes, onions, lettuce, and celery. J. Agric. Food Chem. 1997, 45, 590-595. [CrossRef] 
18. Stewart, A.J.; Bozonnet, S.; Mullen, W.; Jenkins, G.I.; Lean, M.E.J.; Crozier, A. Occurrence of flavonols in tomatoes and tomatobased products. J. Agric. Food Chem. 2000, 48, 2663-2669. [CrossRef]

19. Young, L.Y.; Rivera, M.D. Methanogenic degradation of four phenolic compounds. Water Res. 1985, 19, 1325-1332. [CrossRef]

20. Barz, W.H.; Hoesel, W. Metabolism and Degradation of Phenolic Compounds in Plants. In Biochemistry of Plant Phenolics. Recent Advances in Phytochemistry; Swain, T., Harbone, J.B., van Sumere, C.F., Eds.; Springer: Boston, MA, USA, 1979 ; Volume 12. [CrossRef]

21. Cho, D.-H.; Lim, S.-T. Changes in phenolic acid composition and associated enzyme activity in shoot and kernel fractions of brown rice during germination. Food Chem. 2018, 256, 163-170. [CrossRef] [PubMed]

22. Silva, E.; Nogueira, J. Efeito do calor na atividade da polifenol oxidase e peroxidase em algumas frutas e hortaliças. Anais da Escola Superior de Agricultura Luiz de Queiroz 1983, 40, 137-161. [CrossRef]

23. McCoy, R.M.; Utturkar, S.M.; Crook, J.W.; Thimmapuram, J.; Widhalm, J.R. The origin and biosynthesis of the naphthalenoid moiety of juglone in black walnut. Hortic. Res. 2018, 5, 67. [CrossRef]

24. Strack, D. 10—Phenolic metabolism. In Plant Biochemistry; Dey, P.M., Harborne, J.B., Eds.; Academic Press: London, UK, 1997; pp. 387-416.

25. Strugstad, M.; Despotovski, S. A summary of extraction, synthesis, properties, and potential uses of juglone: A literature review. J. Ecosyst. Manag. 2013, 13, 1-16.

26. Gries, G.A. Juglone, the active agent in walnut toxicity. North. Nut Grow. Assoc. Annu. Rep. 1943, 34, 52-55.

27. Daglish, C. The determination and occurrence of a hydrojuglone glucoside in the walnut. Biochem. J. 1950, 47, 458-462. [CrossRef]

28. Medic, A.; Jakopic, J.; Hudina, M.; Solar, A.; Veberic, R. Identification and quantification of the major phenolic constituents in Juglans regia L. peeled kernels and pellicles, using HPLC-MS/MS. Food Chem. 2021, 352, 129404. [CrossRef]

29. Medic, A.; Solar, A.; Hudina, M.; Veberic, R. Phenolic response to walnut anthracnose (Ophiognomonia leptostyla) infection in different parts of Juglans regia husks, using HPLC-MS/MS. Agriculture 2021, 11, 659. [CrossRef]

30. Medic, A.; Jakopic, J.; Solar, A.; Hudina, M.; Veberic, R. Walnut (J. regia) agro-residues as a rich source of phenolic compounds. Biology 2021, 10, 535. [CrossRef] [PubMed]

31. Ellendorff, T.; Brun, R.; Kaiser, M.; Sendker, J.; Schmidt, T.J. PLS-prediction and confirmation of hydrojuglone glucoside as the antitrypanosomal constituent of Juglans spp. Molecules 2015, 20, 10082-10094. [CrossRef]

32. Medic, A.; Zamljen, T.; Hudina, M.; Veberic, R. Identification and quantification of naphthoquinones and other phenolic compounds in leaves, petioles, bark, roots, and buds of Juglans regia L., Using HPLC-MS/MS. Horticulturae 2021, 7, 326. [CrossRef]

33. Cianciosi, D.; Forbes-Hernández, T.Y.; Afrin, S.; Gasparrini, M.; Reboredo-Rodriguez, P.; Manna, P.P.; Zhang, J.; Bravo Lamas, L.; Martínez Flórez, S.; Agudo Toyos, P.; et al. Phenolic compounds in honey and their associated health benefits: A review. Molecules 2018, 23, 2322. [CrossRef] [PubMed]

34. Shahidi, F.; Varatharajan, V.; Oh, W.Y.; Peng, H. Phenolic compounds in agri-food by-products, their bioavailability and health effects. J. Food Bioact. 2019, 5, 57-119. [CrossRef]

35. Minatel, I.O.; Borges, C.V.; Ferreira, M.I.; Gomez, H.A.G.; Chen, C.-Y.O.; Lima, G.P.P. Functional Properties, Impact of Processing and Bioavailability. In Phenolic Compounds. Biological Activity; IntechOpen: London, UK, 2017; Volume 8, pp. 1-24. [CrossRef] 